\title{
Increased Prevalence, Predictors, and In-Group Differences of Forced Sex and Physical Dating Violence among Trans/Gender Diverse Youth
}

\author{
Shanna K. Kattari ${ }^{1, *(\mathbb{D})}$, Brittanie Atteberry-Ash ${ }^{2}$, Christopher Collins ${ }^{3}$ (D), Leonardo Kattari ${ }^{4}$ (D) \\ and Vern Harner ${ }^{5}(\mathbb{D}$ \\ 1 School of Social Work and the Department of Women's and Studies, University of Michigan, \\ Ann Arbor, MI 48109, USA \\ 2 School of Social Work, University of Texas Arlington, Arlington, TX 76019, USA; brittanie.ash@uta.edu \\ 3 College of Social Work, Florida State University, Tallahassee, FL 32304, USA; cjc11e@my.fsu.edu \\ 4 School of Social Work, Michigan State University, Lansing, MI 48824, USA; kattaril@msu.edu \\ 5 School of Social Work, University of Washington, Seattle, WA 98105, USA; vharner@uw.edu \\ * Correspondence: skattari@umich.edu
}

check for updates

Citation: Kattari, Shanna K., Brittanie Atteberry-Ash, Christopher Collins, Leonardo Kattari, and Vern Harner. 2021. Increased Prevalence, Predictors, and In-Group Differences of Forced Sex and Physical Dating Violence among Trans/Gender Diverse Youth. Social Sciences 10: 236. https://doi.org/10.3390/ socsci10060236

Academic Editor: Nigel Parton

Received: 13 May 2021

Accepted: 16 June 2021

Published: 21 June 2021

Publisher's Note: MDPI stays neutral with regard to jurisdictional claims in published maps and institutional affiliations.

Copyright: (c) 2021 by the authors. Licensee MDPI, Basel, Switzerland. This article is an open access article distributed under the terms and conditions of the Creative Commons Attribution (CC BY) license (https:// creativecommons.org/licenses/by/ $4.0 /)$

\begin{abstract}
Forced sex and dating violence are too common among young people and rates are higher for young transgender and gender diverse (TGD) individuals. However, the TGD youth population has differential experiences across gender, race, age, sexual orientation, and other identity factors. This study, using data from the 2015 Healthy Kids Colorado Survey, explores these differential withingroup experiences of forced sex and dating violence. Findings indicate that sexual minorities who are also TGD are 2.45-3.73 times more likely to experience forced sex and physical dating violence than their TGD heterosexual peers. Individuals who are transfeminine (4.49 times), transmasculine (2.52 times), and nonbinary (3.86 times) are more likely to experience forced sex, as well as physical dating violence (transfeminine (4.01 times), transmasculine (2.91 times), and nonbinary (4.77 times)), as compared to those individuals questioning their gender. Black individuals (3.93 times) and Multiracial individuals (2.39 times) are more likely to experience dating violence than their White counterparts. Age was related to increased experience of forced sex, with individuals being 1.34 times more likely to have experienced this per year increase of age. These findings indicate the need for more trans-inclusive youth programing around sexual violence and dating violence, as well as taking a more intersectional and personalized approach to prevention work.
\end{abstract}

Keywords: forced sex; dating violence; intimate partner violence; transgender; gender diverse; nonbinary; gender identity; youth

\section{Introduction}

Experiences of forced sex and dating violence are unfortunately too common among young people. However, these rates are significantly higher for young transgender and gender diverse (TGD) individuals (Dank et al. 2014; Murchison et al. 2019). It is important to note, though, that the TGD population is not homogenous and there are differential experiences within this group, many of which have not previously been addressed. This study explores how age, race, sexual orientation, and gender intersect with TGD status regarding experiences of both forced sex and dating violence.

\subsection{Transgender and Gender Diverse Identities}

Language and terminology are consistently evolving in the transgender and gender diverse (TGD) community. In this study, the terms "transgender" and "gender diverse" are being used as an inclusive way to encompass the multitude of gender identities of individuals whose conceptualization of their gender does not fit with societal assumptions and expectations based on their sex assigned at birth or perceptions of the general public. 
This includes, but is not limited to, individuals who may use terms such as "nonbinary", "genderqueer", "trans man", "trans woman", or "agender". While there is no accurate estimate of the TGD population in the United States due to governmental census and survey data collection limitations, current estimated percentages are $0.6 \%$ for adults and range from $0.7 \%$ to $1.8 \%$ for youth (Herman et al. 2017; Johns et al. 2019). Cisgender refers to individuals who are not transgender.

\subsection{Forced Sex and Sexual Assault among Youth in General}

Sexual assault is a broad term used to describe nonconsensual sexual acts, including different forms of rape, molestation, and sexual abuse (Kaufman 2008). This includes sexual acts regardless of whether penetration is present. The situation surrounding the assault might include components of physical force or psychological/social coercion. While it is widely accepted that sexual assaults are underreported, studies show that adolescents and young adults aged 12 to 34 years have among the highest rates of sexual assault (CrawfordJakubiak et al. 2017; Kaufman 2008; Planty et al. 2013). While the incidence of sexual violence in children increases beginning at age 8 , risk of this violence peaks in adolescents aged 14 to 17 years (Finkelhor et al. 2009) Roughly, 66\% to $75 \%$ of adolescent sexual assaults are perpetrated by someone who is known to the adolescent, though older adolescents are most commonly victimized during social encounters (e.g., dates) (Muram et al. 1995; Peipert and Domagalski 1994). Adolescents and young adults who are gender/sexual minorities and/or Black, Indigenous, or other people of color (BIPOC) also have increased odds of being sexually assaulted (Coulter et al. 2017).

Forced sex is a specific type of sexual assault: being physically forced to have sexual intercourse. The 2017 Youth Risk Behavior Surveillance System (NYRBSS) found that, while $9.7 \%$ of all high school youth had experienced sexual violence, $15.2 \%$ of female high school students had experienced forced sex specifically (Kann et al. 2018). However, 17.8\% of lesbian, gay, and bisexual (LGB) high school students had been physically forced to have sex, compared to $5.4 \%$ of heterosexual students overall (Kann et al. 2016a). Having experienced sexual assault is linked to depression, bullying, and suicidality (Atteberry-Ash et al. 2020; Chen et al. 2010).

\subsection{Forced Sex and Sexual Assault among TGD Youth}

The lifetime prevalence rate of sexual assault among TGD adults in the United States is estimated to be $47 \%$ (James et al. 2016). It can be theorized, based on the disproportionate number of TGD adults that have experienced sexual victimization, that similar disproportionalities exist among TGD youth. Previous research relying on relatively small samples of TGD youth has found evidence that rates of sexual victimization exceed $50 \%$ among TGD youth (Garofalo et al. 2006; Sterzing et al. 2019).

Murchison et al. (2019), using a nationally representative sample of 3673 TGD youth, found that the 12-month prevalence rate of sexual assault was $25.9 \%$. Those TGD youth most at risk were nonbinary youth assigned female at birth $(27 \%)$ and transgender boys (26.5\%) (Murchison et al. 2019). While lower than previous studies with smaller samples, these numbers still exceed the average for cisgender peers of TGD youth. Another recent study examining the intersections of gender and sexual orientation found that TGD youth were 6.01 to 9.51 times more likely to have experienced forced sex (depending on their sexual orientation) than their cisgender heterosexual counterparts (Atteberry-Ash et al. 2020). This study found that trans high schoolers who were LGB had the highest prevalence of forced sex, though differences between trans adolescents of different genders was not examined (Atteberry-Ash et al. 2020).

TGD youth who have experienced sexual victimization report experiencing myriad problems as a result of sexual victimization. Problematic substance use (Testa et al. 2012; Coulter et al. 2015), psychiatric distress (Fernández-Rouco et al. 2016), suicidal ideation and attempt (Fernández-Rouco et al. 2016; Testa et al. 2012; Wyss 2004), and dropping 
out of school (Wyss 2004) are all potential problems TGD youth who have been sexually victimized face.

\subsection{Dating Violence among Youth in General}

The Centers for Disease Control and Prevention has a multi-faceted definition of dating violence, which includes physical, sexual, psychological, and stalking behaviors (Centers for Disease Control and Prevention 2014). However, most studies tend to focus on one or two of these types of dating violence, such as physical violence (Hamby and Turner 2013). Emerging adults with a history of experiencing dating violence as teens or adolescents have higher rates of depression, substance use, and suicidality, and they are more likely to be victimized by intimate partners in the future (Foshee et al. 2013; Exner-Cortens et al. 2013; Roberts et al. 2003; Smith et al. 2003).

An analysis of the 2017 NYRBSS (Kann et al. 2018) found that among those who had dated, $9.1 \%$ of female students and $6.5 \%$ of male students reported experiencing physical teen dating violence in the prior year. The prevalence of physical dating violence ranged from $5.2 \%$ to $14.1 \%$ across 36 states (median $8.7 \%$ ). Overall, $16.9 \%$ and $16.8 \%$ of female and male students, respectively, who were LGB reported physical dating violence. Regardless of sexual identity, students who had sexual contact with members of the same sex had the highest rates of physical dating violence $(19.8 \%$ and $21.4 \%$ of female and male students, respectively). While $8.6 \%$ of students in Colorado experienced physical dating violence, $11.3 \%$ of female students, $6.1 \%$ of male students, and $6.5 \%$ of straight students had experienced physical dating violence in the prior year. LGB students $(19.1 \%)$ had the highest rate of physical dating violence of any subgroup analyzed in Colorado. Further, this study found that $6.9 \%$ of students had experienced sexual dating violence in the year prior to the survey, with $10.7 \%$ of female students and $2.8 \%$ of male students reporting this. While the 2013 NYRBSS data did not show that physical or sexual dating violence varied between students of different races, in 2017, Black (13.1\%) and Hispanic (9.2\%) female students had higher rates of physical dating violence than White female $(8.0 \%)$, Black male $(7.1 \%)$, and Hispanic male (5.9\%) students (Kann et al. 2016b, 2018). Trend analysis of the 2013, 2015, and 2017 NYRBSS data found a significant linear decrease (10.3-8.0\%) in the overall prevalence of physical dating violence among students who dated in the year prior to the survey (Kann et al. 2018).

\subsection{Dating Violence among TGD Youth}

Dating violence is consistently found to be more pervasive among TGD youth than their cisgender counterparts, despite also being greatly understudied. Dank and colleagues (2014) found that TGD youth experience higher rates of dating violence than their nonTGD peers, noting that $59.0 \%$ reported having ever experienced psychological dating violence; $89.0 \%$ having ever experienced physical dating violence; and $69.0 \%$ having ever experienced sexual dating violence. Another recent study noted that among transgender young people, $27.5 \%$ of transmasculine youth, $39.7 \%$ of transfeminine youth, and $48.5 \%$ of nonbinary youth had experienced violence from a dating partner in the past 12 months (Walls et al. 2019).

Espelage and colleagues (2016) found that TGD youth who had experienced dating violence victimization experience poorer mental health outcomes (e.g., anxiety, suicidality) than their cisgender peers who experienced dating violence victimization. Health and mental health disparities among TGD youth are increasingly explained using the minority stress model (Espelage et al. 2016). The increased social stressors that TGD youth face, such as peer victimization (Hatchel et al. 2018; Norris and Orchowski 2020), parental rejection (Robinson 2018), and child maltreatment (Rimes et al. 2017) all increase stress, and thereby the vulnerability, of TGD youth to dating violence.

The increased vulnerability to dating violence is problematic for TGD youth, as youth who experience dating violence are already at heightened risk for substance use, sexual risk-taking behaviors, and suicidality (Exner-Cortens et al. 2013; Silverman et al. 2001). The 
social stressors that increase the likelihood of teen dating violence for TGD coupled with the severe impact of experiencing teen dating violence are serious points of consideration in the body of literature on TGD teen dating violence as it relates to severity of outcomes.

\subsection{Hypotheses}

Given the existing high rates of forced sex and dating violence within the TGD youth population, there is likely to be high rates of these experiences throughout the sample. Based on existing evidence, we hypothesize that these rates will be even higher among transfeminine, transmasculine, and nonbinary individuals, and non-heterosexual individuals in both contexts, as well as higher for Black and Latino/Hispanic individuals.

\section{Materials and Methods}

\subsection{Data}

Data for this study come from the 2015 Healthy Kids Colorado Survey, a statewide survey of public middle and high schools in Colorado. Based on public school statewide enrollment, schools and then classrooms were randomly selected to participate in the survey. Randomly selected district superintendents and school principals could decide to refuse to take part in the survey. Further, superintendents or principals could remove certain questions from the survey. All participating schools notified parents and guardians of the survey and that participation was voluntary; however, districts determined whether or not the survey was opt in or opt out. Data were weighted to best represent enrollment in Colorado public schools. Weights accounted for student and school nonresponse and nonparticipation, sampling design, and demographic differences in the sample and school population.

The 2015 Healthy Kids Colorado Survey included a total of 15,970 high school students. Three schools opted to not include questions examined in the current study. Given this challenge, the student responses from those schools were dropped from the analytic sample $(n=395)$. Next, all records that did not answer the dependent variable inquiring about experiences of forced sex were dropped $(n=987)$. An additional 364 records were dropped due to participants indicating they did not understand the question that inquired about transgender identity. Given that the current study examines outcomes only for students who identified under the transgender umbrella, all cisgender respondents were dropped $(n=13,402)$, as well as all missing cases for gender identity $(n=259)$. Lastly, all participants who noted an age under 14 were dropped $(n=36)$, as this is outside the typical age range for high school students in Colorado. These steps brought the analytic sample to 564 participants. Next, data were examined for missingness.

Missing data for the independent variables ranged from a low of $0 \%$ for age and gender identity to a high of $3.6 \%$ for sexual orientation. Given that no variables were missing more than $10 \%$ of the time, listwise deletion was used (Bennett 2001). This brought the final analytic sample to 499 for the dependent variable examining forced sex. For the dependent variable that examined dating violence, respondents who had not dated in the last year were dropped from the sample $(n=163)$ and those who did not answer the question were also dropped $(n=2)$. The final analytic sample for the second dependent variable examining data violence consisted of 334 students.

\subsection{Measures}

The dependent variable of experiencing forced sex was captured with the question "Have you ever been physically forced to have sexual intercourse when you did not want to?" with a yes/no response set. Those who indicated "yes" were coded as 1 with all others were coded as 0 . To capture the dependent variable regarding dating violence, respondents were asked, "During the past 12 months, how many times did someone you were dating or going out with physically hurt you on purpose? (Count such things as being hit, slammed into something, or injured with an object or weapon)", with a response set of "I did not date or go out with anyone during the past 12 months", "0 times", "1 time", "2 or 3 times", 
and " 4 or more times". Participants who did not answer were dropped, with the remaining responses coded to indicate if respondents had experienced dating violence (yes/no).

Age was gathered with the question "How old are you?" The response set included the following options: "12 years old or younger", "13 years old", "14 years old", "15 years old", "16 years old", "17 years old", or "18 years old or older" (recoded to 18). In order to gather information on race/ethnicity, respondents were asked two questions. The first was "What is your race? (select one or more)". Response options included "American Indian or Alaska Native", "Asian", "Black or African American", "Native Hawaiian or Other Pacific Islander", or "White". The second question was "Are you Hispanic or Latino?" with a yes/no response set. These two questions were combined, and a new race/ethnicity variable was created, which included the new category of Multiracial. For the newly created race/ethnicity variable, post hoc tests were run to determine how to collapse categories with small numbers of respondents. Given the test results, Native Hawaiian/Alaska Native/Pacific Islander and American Indian were collapsed together.

To gather sexual orientation, respondents answered the question "Which of the following best describes you?" and were given the response set of "heterosexual (straight)", "gay or lesbian", "bisexual", and "not sure" (renamed as questioning). For gender identity, participants were asked, "A transgender person is someone whose biological sex at birth does not match the way they think or feel about themselves. Are you transgender?" with response options of "No, I am not transgender"; "Yes, I am transgender and I think of myself as really a boy or man" (renamed as transmasculine); "Yes, I am transgender and I think of myself as really a girl or woman" (renamed as transfeminine); "Yes, I am transgender and I think of myself in some other way" (renamed as transgender/nonbinary); "I do not know if I am transgender"; and "I do not know what this question is asking".

\subsection{Data Analysis}

Stata 15.0 (STATA Corporation, College Station, TX, USA) was used for all analysis. Survey commands were used to account for the survey design and use of weights. First, descriptive statistics were run, then two separate logistic regressions were run; the first predicts forced sex, the second predicts past year dating violence.

\subsection{Descriptive Statistics}

Descriptive statistics are reported for our two samples; all respondents for the forced sex model $(n=499)$ and then just those who reported experiencing dating violence $(n=334)$ (see Table 1). About a quarter of youth reported experiencing forced sex $(n=129,25.85 \%)$, and $29.64 \%(n=99)$ had experienced dating violence in the past year.

Table 1. Descriptive statistics for all study variables.

\begin{tabular}{|c|c|c|c|c|c|c|c|c|c|}
\hline \multicolumn{2}{|c|}{$\begin{array}{c}\text { Variables } \\
\text { Dependent Variable }\end{array}$} & \multirow{2}{*}{$\begin{array}{c}n \\
370\end{array}$} & $\%$ & & & & & & \\
\hline \multirow[t]{2}{*}{ Forced Sex } & No & & 74.15 & & & & & & \\
\hline & Yes & 129 & 25.85 & & & & & & \\
\hline \multirow[t]{2}{*}{ Dating Violence } & No & 235 & 70.36 & & & & & & \\
\hline & Yes & 99 & 29.64 & & & & & & \\
\hline \multicolumn{2}{|c|}{ Independent Variables } & \multicolumn{2}{|c|}{$\begin{array}{l}\text { Forced Sex Total } \\
\text { Sample }\end{array}$} & \multicolumn{2}{|c|}{$\begin{array}{l}\text { Experienced } \\
\text { Forced Sex }\end{array}$} & \multicolumn{2}{|c|}{$\begin{array}{l}\text { Dating Violence } \\
\text { Total Sample }\end{array}$} & \multicolumn{2}{|c|}{$\begin{array}{c}\text { Experienced } \\
\text { Dating Violence }\end{array}$} \\
\hline \multirow{7}{*}{ Race/ethnicity } & & $n$ & $\%$ & $n$ & $\%$ & $n$ & $\%$ & $n$ & $\%$ \\
\hline & $\mathrm{AI} / \mathrm{AN} / \mathrm{NH} / \mathrm{PI}$ & 16 & 3.21 & 4 & 25.00 & 12 & 3.59 & 5 & 41.67 \\
\hline & Asian & 13 & 2.61 & 2 & 15.38 & 7 & 2.10 & 2 & 28.57 \\
\hline & Black & 17 & 3.41 & 4 & 23.53 & 11 & 3.29 & 6 & 54.55 \\
\hline & Latino/Hispanic & 110 & 22.04 & 24 & 21.82 & 72 & 21.56 & 8 & 11.11 \\
\hline & Multiracial & 126 & 25.25 & 42 & 33.33 & 90 & 26.95 & 41 & 45.56 \\
\hline & White & 217 & 43.49 & 53 & 24.42 & 142 & 42.51 & 37 & 26.06 \\
\hline
\end{tabular}


Table 1. Cont.

\begin{tabular}{|c|c|c|c|c|c|c|c|c|c|}
\hline \multicolumn{2}{|c|}{$\begin{array}{c}\text { Variables } \\
\text { Dependent Variable }\end{array}$} & \multirow{2}{*}{$\begin{array}{c}n \\
132\end{array}$} & \multicolumn{2}{|l|}{$\%$} & \multirow[b]{2}{*}{34.85} & \multirow[b]{2}{*}{91} & \multirow[b]{2}{*}{27.25} & \multirow[b]{2}{*}{28} & \multirow[b]{2}{*}{30.77} \\
\hline Sexual & Bisexual & & 26.45 & 46 & & & & & \\
\hline orientation & Gay/Lesbian & 70 & 14.03 & 19 & 27.14 & 50 & 14.97 & 18 & 36.00 \\
\hline & Heterosexual & 171 & 34.27 & 46 & 32.64 & 120 & 35.93 & 21 & 17.50 \\
\hline & Questioning & 126 & 25.25 & 30 & 23.81 & 73 & 21.86 & 32 & 43.84 \\
\hline \multirow{4}{*}{$\begin{array}{l}\text { Gender } \\
\text { identity }\end{array}$} & Do not Know & 192 & 38.48 & 25 & 13.02 & 120 & 35.93 & 19 & 15.83 \\
\hline & Transfeminine & 80 & 16.03 & 31 & 38.75 & 60 & 17.96 & 23 & 38.33 \\
\hline & Transmasculine & 129 & 25.85 & 33 & 25.58 & 92 & 27.54 & 26 & 28.26 \\
\hline & Trans/Nonbinary & 98 & 19.64 & 40 & 40.82 & 62 & 18.56 & 31 & 50.00 \\
\hline
\end{tabular}

Note: $\mathrm{AI}=$ American Indian, $\mathrm{AN}=$ Alaska Native, $\mathrm{NH}=$ Native Hawaiian, $\mathrm{PI}=$ Pacific Islander.

\section{Results}

\subsection{Prevalence of Forced Sex}

Experiences of forced sex were highest among youth who identified as Multiracial $(33.33 \%)$, followed by American Indian/Alaska Native/Native Hawaiian/Pacific Islander $(25.00 \%)$, White $(24.42 \%)$, Black (23.53\%), and Latino/Hispanic (21.82\%), with Asian students having the lowest incidence of forced sex $(15.38 \%)$. Regarding sexual orientation, prevalence of experiencing forced sex was highest for students who identified as bisexual (34.85\%), followed by heterosexual (32.64\%), and gay or lesbian (27.14\%), with students questioning their sexual orientation having the lowest rates $(23.81 \%)$. With respect to gender identity, transgender/nonbinary students had the highest rates of forced sex (40.82\%), followed closely by transfeminine individuals (38.75\%) and transmasculine individuals $(25.58 \%)$, with those who stated they did not know if they were transgender having the lowest rates of experiencing forced sex (13.02\%).

\subsection{Predictors of Forced Sex}

In examining the model for forced sex, every one-year increase in age was associated with a $34 \%$ increase in the odds of experiencing forced sex (AOR $=1.34,95 \%$ CI [1.13, 1.59]). Compared to students who indicated they did not know if they were transgender or not, transfeminine students $(\mathrm{AOR}=4.49,95 \% \mathrm{CI}[2.34,8.63])$, transmasculine students $(\mathrm{AOR}=2.52,95 \% \mathrm{CI}[1.37,4.62])$, and trans/nonbinary students $(\mathrm{AOR}=3.86,95 \% \mathrm{CI}[2.10$, 7.07]) were all at elevated odds of experiencing forced sex.

\subsection{Prevalence of Dating Violence}

Experiences of dating violence were highest among youth who identified as Black (54.55\%), followed by youth who identified as Multiracial (45.56\%), American Indian/Alaska Native/Native Hawaiian/Pacific Islander (41.67\%), Asian (28.57\%), and White (26.06\%), with Latino/Hispanic students having the lowest incidence of dating violence (11.11\%). Regarding sexual orientation, prevalence of experiencing past year dating violence was highest for questioning students (43.84\%), followed by gay or lesbian students (36.00\%) and bisexual students $(30.77 \%)$, with heterosexual students having the lowest rates $(17.50 \%)$. With respect to gender identity, transgender/nonbinary students had the highest rates of experiencing dating violence $(50.00 \%)$, followed by transfeminine students $(38.33 \%)$ and transmasculine students $(28.26 \%)$, with those who stated they did not know if they were transgender having the lowest rates $(15.83 \%)$.

\subsection{Predictors of Dating Violence}

In examining the model for dating violence, compared to White respondents, Black respondents had almost four times the odds of experiencing dating violence $(\mathrm{AOR}=3.93$, 95\% CI [1.01, 15.36]), while Multiracial participants had more than two times the odds of experiencing past year dating violence $(\mathrm{AOR}=2.39,95 \% \mathrm{CI}[1.30,4.41])$. Compared to transgender youth who indicated they were heterosexual, lesbian/gay respondents 
$(\mathrm{AOR}=2.48,95 \% \mathrm{CI}[1.09,5.67])$ and bisexual respondents $(\mathrm{AOR}=2.45,95 \% \mathrm{CI}[1.16,5.17])$ had over two times the odds of experiencing past year dating violence, while those who were questioning their sexual orientation (AOR $=3.73,95 \% \mathrm{CI}[1.77,7.89])$ had almost four times the odds of experiencing dating violence in the past year. Lastly, compared to students who indicated they did not know if they were transgender or not, transfeminine students $(\mathrm{AOR}=4.01,95 \% \mathrm{CI}[1.81,8.89])$, transmasculine students $(\mathrm{AOR}=2.91,95 \% \mathrm{CI}$ $[1.38,6.14])$, and transgender/nonbinary students (AOR $=4.77,95 \% \mathrm{CI}[2.23,10.19])$ were all at elevated odds of experiencing dating violence in the past year. See Table 2.

Table 2. Logistic regression models of how age, race, and sexual orientation relate to DV.

\begin{tabular}{|c|c|c|}
\hline \multirow{4}{*}{ Variable } & Regression 1 & Regression 2 \\
\hline & Forced Sex & DV \\
\hline & $N=499$ & $N=334$ \\
\hline & AOR $[95 \% \mathrm{CI}]$ & AOR $[95 \% \mathrm{CI}]$ \\
\hline Age & $1.34[1.13,1.59]^{* * *}$ & $1.24[1.00,1.54]$ \\
\hline \multicolumn{3}{|l|}{ Race (White) } \\
\hline $\mathrm{AI} / \mathrm{AN} / \mathrm{NH} / \mathrm{PI}$ & $0.99[0.28,3.49]$ & $2.63[0.68,10.08]$ \\
\hline Asian & $0.46[0.09,2.27]$ & $0.80[0.13,4.93]$ \\
\hline Black & $0.90[0.26,3.05]$ & $3.93[1.01,15.36]$ * \\
\hline Latino/Hispanic & $1.01[0.56,1.84]$ & $0.46[0.19,1.10]$ \\
\hline Multiracial & $1.41[0.84,2.37]$ & $2.39[1.30,4.41]^{*}$ \\
\hline \multicolumn{3}{|l|}{$\begin{array}{l}\text { Sexual orientation } \\
\text { (heterosexual) }\end{array}$} \\
\hline Gay/lesbian & $1.21[0.60,2.44]$ & $2.48[1.09,5.67]$ * \\
\hline Bisexual & $2.50[1.39,4.48]^{* *}$ & $2.45[1.16,5.17]^{*}$ \\
\hline Questioning & $1.52[0.82,2.81]$ & $3.73[1.77,7.89]^{* * *}$ \\
\hline \multicolumn{3}{|c|}{ Gender (do not know) } \\
\hline Transfeminine & $4.49[2.34,8.63]^{* * *}$ & $4.01[1.81,8.89]^{* * *}$ \\
\hline Transmasculine & $2.52[1.37,4.62] * *$ & $2.91[1.38,6.14]^{* *}$ \\
\hline Trans/Nonbinary & $3.86[2.10,7.07]^{* * *}$ & $4.77[2.23,10.19]^{* * *}$ \\
\hline
\end{tabular}

Note: Odds ratios are adjusted for the other predictors in the model. DV = Dating Violence. AI = American Indian, $\mathrm{AN}=$ Alaska Native, $\mathrm{NH}=$ Native Hawaiian, $\mathrm{PI}=$ Pacific Islander. ${ }^{*} p<0.05,{ }^{* *} p \leq 0.01,{ }^{* * *} p \leq 0.001$.

\section{Discussion and Implications}

In the analysis of this subsample of high school students who are TGD or unsure about their gender, there are very high rates of violence, with almost a quarter having experienced forced sex of some kind in the past year, and approximately $30 \%$ having experienced partner violence in the same time frame. While these numbers by themselves are alarming, breaking it down by identities within this TGD/unsure sample reveals further differential experiences within this population.

As compared with individuals who are still figuring out or questioning their gender, transmasculine youth were 2.52 times more likely to have experienced forced sex in the past year, with even higher rates for nonbinary participants (3.86 times more likely) and transfeminine participants (4.49 times more likely). This pattern holds somewhat for dating violence experiences, although here, nonbinary individuals were almost five times more likely to have had these experiences in the previous 12 months, with transfeminine individuals being approximately four times as likely and transmasculine individuals slightly under three times as likely, compared to their peers questioning their gender. We can hypothesize that individuals are more likely to experience these negative events after they come out as one of these identities, as compared to their peers who are still exploring their true genders.

We see patterns with sexual orientation, too, with bisexual individuals and those questioning their sexual orientation having higher likelihood of both forced sex and dating violence compared to their heterosexual peers, and gay and lesbian individuals also experi- 
encing increased likelihood of dating violence compared to their heterosexual counterparts. This speaks to the need to look at the intersection of sexual orientation and gender identity rather than only examining one or the other.

When it comes to race, there were no significant findings regarding forced sex. However, as related to experiences of dating violence in the past year, Multiracial individuals were approximately two-and-a-half times as likely to have had these experiences as their White counterparts, and Black participants were almost four times as likely, indicating a need to also explore the intersection of race and gender when it comes to dating violence. On the other hand, age was not a significant factor in dating violence but was significant for forced sex, the likelihood increasing with age.

These findings follow extant research that found in-group differences within the TGD population in mental health (Kattari et al. 2020), forced sex (Atteberry-Ash et al. 2020), intimate partner violence (Walls et al. 2019), and access to health care (Kattari et al. 2019). Collectively, this demonstrates the need for surveys and forms to move away from the "man/woman/transgender" model that is so common and toward ones that allow for more nuance both within and across gender.

Given the extremely high rates of both forced sex and dating violence in the TGD youth population, it is clear that there is a need for prevention programs that are both inclusive and affirming of young people with these identities. Traditional programs that focus on binary genders and heterosexual assumptions regarding relationships simply are not designed for these individuals and are therefore ineffective. Including TGD adults and youth as participants in the designing of these programs to be sure that they reach the intended audience and are more effective would be a good first step. More intersectional approaches are needed to ensure that these programs are not only inclusive of TGD and lesbian, gay, bisexual, queer, and questioning youth, but are also inclusive of BIPOC youth, who may have differential rates of experiencing violence as well.

There is also a demonstrated need for better screening for intimate partner violence for this population in various settings, whether through their mental health providers, primary care physicians, or even their high school counselor's office. Several scholars are working on difference scales and assessments to better meet the unique needs of this group (Peitzmeier et al. 2019; Stephenson et al. 2020).

In addition to improving prevention programs, there also needs to be clear support for the TGD young people who experience forced sex and/or dating violence. This means that rape crisis centers, shelters for people who have experienced intimate partner violence, shelters for those experiencing homelessness, mental health providers, and others need to be intentional and thoughtful regarding how to ensure that TGD clients feel safe and welcome. This could include using intake forms that ask for pronouns and correct name, having gender inclusive bathrooms, making sure that spaces are not divided by "gender" (which is usually relegated to sex assigned at birth), and hiring TGD staff who understand the unique needs of this population.

\section{Limitations}

Due to the cross-sectional nature of these findings, there are limitations on causality and temporal ordering, as this study assessed only a snapshot in time. Additionally, as this was secondary data analysis, we did not have control over how questions were framed. Given the rapidly evolving language pertaining to gender identity, many participants may have not felt represented in the options given. As a result, some TGD respondents may not have ended up in our sample and there may be further in-group differences we were unable to assess. It should also be noted that the data used in our study come from a state that enumerates non-discrimination protections for TGD individuals. Given this, it may not be generalizable to TGD young people in all states in the United States, particularly since some states are regressing in their protections for this population. As information about gender identity and sexual orientation is not often collected on general surveys, future research on youth, including health, violence, and wellbeing should include these 
variables to better allow for a deeper exploration of the nuances experienced by members of this population. Lastly, racial distribution in Colorado may be different than that of other states.

\section{Conclusions}

Forced sex and dating violence are extremely charged issues for all young people, and the rates of each are much higher among TGD youth than the population as a whole. Even within this sub-population, there are differential rates of these experiences across race, age, gender, and sexual orientation. Educators, social service professionals, and others who work with young people should be prepared to explore the unique needs of this population in an effort to reduce the rate of these experiences. From additional training on working with diverse populations to support services designed specifically for the unique needs of these marginalized groups, and from hiring members of the TGD population to organizing major policy shifts, there are many ways to better support these individuals and communities when it comes to preventing forced sex and dating violence, and helping survivors of these issues.

Author Contributions: Conceptualization, S.K.K. and B.A.-A.; methodology, B.A.-A. and L.K.; software, B.A.-A.; validation, B.A.-A. and S.K.K.; formal analysis, B.A.-A.; literature, S.K.K., C.C., L.K., and V.H.; data curation, L.K.; writing, B.A.-A., S.K.K., C.C., L.K., and V.H.; supervision, S.K.K. All authors have read and agreed to the published version of the manuscript.

Funding: This research received no external funding.

Institutional Review Board: This study was determined to not meet the definition of "research with human subjects" as defined by the Office for Human Research Protections (OHRP).

Informed Consent Statement: Informed consent was obtained from all participants involved in the study.

Data Availability Statement: Data is available by request by contacting the first author.

Conflicts of Interest: The authors declare no conflict of interest.

\section{References}

Atteberry-Ash, Brittanie, N. Eugene Walls, Shanna K. Kattari, Sarah M. Peitzmeier, Leonardo Kattari, and Lisa Langenderfer-Magruder. 2020. Forced sex among youth: Accrual of risk by gender identity, sexual orientation, mental health and bullying. Journal of LGBT Youth 17: 193-213. [CrossRef]

Bennett, Derrick A. 2001. How can I deal with missing data in my study? Australian and New Zealand Journal of Public Health 25: 464-69. [CrossRef] [PubMed]

Centers for Disease Control and Prevention. 2014. Understanding Teen Dating Violence: Fact Sheet. Available online: https: / / www.cdc.gov/violenceprevention/pdf/teen-dating-violence-2014-a.pdf (accessed on 17 June 2021).

Chen, Laura P., M. Hassan Murad, Molly L. Paras, Kristina M. Colbenson, Amelia L. Sattler, Erin N. Goranson, Mohamed B. Elamin, Richard J. Seime, Gen Shinozaki, Larry J. Prokop, and et al. 2010. Sexual abuse and lifetime diagnosis of psychiatric disorders: Systematic review and meta-analysis. In Mayo Clinic Proceedings. Amsterdam: Elsevier, vol. 85, pp. 618-29.

Coulter, Robert W. S., John R. Blosnich, Leigh A. Bukowski, A. L. Herrick, Daniel E. Siconolfi, and Ron D. Stall. 2015. Differences in alcohol use and alcohol-related problems between transgender- and nontransgender-identified young adults. Drug and Alcohol Dependence 154: 251-59. [CrossRef] [PubMed]

Coulter, Robert WS, Christina Mair, Elizabeth Miller, John R. Blosnich, Derrick D. Matthews, and Heather L. McCauley. 2017. Prevalence of past-year sexual assault victimization among undergraduate students: Exploring differences by and intersections of gender identity, sexual identity, and race/ethnicity. Prevention Science 18: 726-36. [CrossRef]

Crawford-Jakubiak, James E., Elizabeth M. Alderman, John M. Leventhal, and Committee on Child Abuse and Neglect. 2017. Care of the adolescent after an acute sexual assault. Pediatrics 139: E20164243. [CrossRef]

Dank, Meredith, Pamela Lachman, Janine M. Zweig, and Jennifer Yahner. 2014. Dating violence experiences of lesbian, gay, bisexual, and transgender youth. Journal of Youth and Adolescence 43: 846-57. [CrossRef]

Espelage, Dorothy L., Gabriel J. Merrin, and Tyler Hatchel. 2016. Peer victimization and dating violence among LGBTQ youth. Youth Violence and Juvenile Justice 16: 156-73. [CrossRef]

Exner-Cortens, Deinera, John Eckenrode, and Emily Rothman. 2013. Longitudinal associations between teen dating violence, victimization and adverse health outcomes. Pediatrics 131: 71-78. [CrossRef] 
Fernández-Rouco, Noelia, Andrés A. Fernández-Fuertes, Rodrigo J. Carcedo, Susana Lázaro-Visa, and Eva Gómez-Pérez. 2016. Sexual violence history and welfare in transgender people. Journal of Interpersonal Violence 32: 2885-907. [CrossRef]

Finkelhor, David, Heather Turner, Richard Ormrod, and Sherry L. Hamby. 2009. Violence, abuse, and crime exposure in a national sample of children and youth. Pediatrics 124: 1411-23. [CrossRef]

Foshee, Vangie Ann, Heath Luz McNaughton Reyes, Nisha C. Gottfredson, Ling-Yin Chang, and Susan T. Ennett. 2013. A longitudinal examination of psychological, behavioral, academic, and relationship consequences of dating abuse victimization among a primarily rural sample of adolescents. Journal of Adolescent Health 53: 723-29. [CrossRef]

Garofalo, Robert, Joanne Deleon, Elizabeth Osmer, Mary Doll, and Gary W. Harper. 2006. Overlooked, misunderstood and at-risk: Exploring the lives and HIV risk of ethnic minority male-to-female transgender youth. Journal of Adolescent Health 38: 230-36. [CrossRef] [PubMed]

Hamby, Sherry, and Heather Turner. 2013. Measuring teen dating violence in males and females: Insights from the National Survey of Children's Exposure to Violence. Psychology and Violence 3: 323-39. [CrossRef]

Hatchel, Tyler, Alberto Valido, Kris T. De Pedro, Yuanhong Huang, and Dorothy L. Espelage. 2018. Minority stress among transgender adolescents: The role of peer victimization, school belonging, and ethnicity. Journal of Child and Family Studies 28: 2467-76. [CrossRef]

Herman, Jody L., Andrew R. Flores, Taylor N. T. Brown, Bianca D. M. Wilson, and Kerith J. Conron. 2017. Age of Individuals Who Identify as Transgender in the United States. Los Angeles: The Williams Institute.

James, Sandy, Jody Herman, Susan Rankin, Mara Keisling, Lisa Mottet, and Ma'ayan Anafi. 2016. The Report of the 2015 U.S. Transgender Survey. Washington, DC: National Center for Transgender Equality.

Johns, Michelle M., Richard Lowry, Jack Andrzejewski, Lisa C. Barrios, Zewditu Demissie, Timothy McManus, Catherine N. Rasberry, Leah Robin, and J. Michael Underwood. 2019. Transgender identity and experiences of violence victimization, substance use, suicide risk, and sexual risk behaviors among high school students-19 states and large urban school districts, 2017. Morbidity and Mortality Weekly Report 68: 67. [CrossRef]

Kann, Laura, Emily O’Malley Olsen, Tim McManus, William A. Harris, Shari L. Shanklin, Katherine H. Flint, Barbara Queen, Richard Lowry, David Chyen, Lisa Whittle, and et al. 2016a. Sexual identity, sex of sexual contacts, and health-related behaviors among students in grades 9-12-United States and selected sites, 2015. MMWR Surveillance Summaries 65: 1-202. [CrossRef]

Kann, Laura, Tim McManus, William A. Harris, Shari L. Shanklin, Katherine H. Flint, Joseph Hawkins, Barbara Queen, Richard Lowry, Emily O'Malley Olsen, David Chyen, and et al. 2016b. Youth risk behavior surveillance-United States, 2015. MMWR Surveillance Summaries 65: 1-174. [CrossRef]

Kann, Laura, Tim McManus, William A. Harris, Shari L. Shanklin, Katherine H. Flint, Barbara Queen, Richard Lowry, David Chyen, Lisa Whittle, Jemekia Thornton, and et al. 2018. Youth risk behavior surveillance-United States, 2017. MMWR Surveillance Summaries 67: 1-114. [CrossRef] [PubMed]

Kattari, Shanna K., Brittanie Atteberry-Ash, M. Killian Kinney, N. Eugene Walls, and Leonardo Kattari. 2019. One size does not fit all: Differential transgender health experiences. Social Work in Health Care 58: 899-917. [CrossRef]

Kattari, Shanna K., Leonardo Kattari, Ian Johnson, Ashley Lacombe-Duncan, and Brayden A. Misiolek. 2020. Differential Experiences of Mental Health among Trans/Gender Diverse Adults in Michigan. International Journal of Environmental Research and Public Health 17: 6805. [CrossRef]

Kaufman, Miriam. 2008. Care of the adolescent sexual assault victim. Pediatrics 122: 462-70. [CrossRef]

Muram, David, Barbara R. Hostetler, Claudette E. Jones, and Patricia M. Speck. 1995. Adolescent victims of sexual assault. Journal of Adolescent Health 17: 372-75. [CrossRef]

Murchison, Gabriel R., Madina Agénor, Sari L. Reisner, and Ryan J. Watson. 2019. School restroom and locker room restrictions and sexual assault risk among transgender youth. Pediatrics 143: e20182902. [CrossRef] [PubMed]

Norris, Alyssa L., and Lindsay M. Orchowski. 2020. Peer victimization of sexual minority and transgender youth: A cross-sectional study of high school students. Psychology of Violence 10: 201-11. [CrossRef]

Peipert, Jeffrey F., and Lisa R. Domagalski. 1994. Epidemiology of adolescent sexual assault. Obstetrics \& Gynecology 84: 867-71.

Peitzmeier, Sarah M., Jaclyn MW Hughto, Jennifer Potter, Madeline B. Deutsch, and Sari L. Reisner. 2019. Development of a novel tool to assess intimate partner violence against transgender individuals. Journal of Interpersonal Violence 34: 2376-97. [CrossRef]

Planty, Michael, Lynn Langton, Christopher Krebs, Marcus Berzofsky, and Hope Smiley-McDonald. 2013. Female Victims of Sexual Violence, 1994-2010; Washington, DC: Bureau of Justice Statistics. Available online: https://www.bjs.gov/content/pub/pdf/ fvsv9410.pdf (accessed on 17 June 2021).

Rimes, Katharine A., Nicola Goodship, Greg Ussher, Dan Baker, and Elizabeth West. 2017. Non-binary and binary transgender youth: Comparison of mental health, self-harm, suicidality, substance use and victimization experiences. International Journal of Transgenderism 20: 230-40. [CrossRef]

Roberts, Timothy A., Jonathan D. Klein, and Susan Fisher. 2003. Longitudinal effect of intimate partner abuse on high-risk behavior among adolescents. Archives of Pediatric Adolescent Medicine 157: 875-81. [CrossRef] [PubMed]

Robinson, Brandon A. 2018. Conditional families and lesbian, gay, bisexual, transgender, and queer youth homelessness: Gender, sexuality, family instability, and rejection. Journal of Marriage and Family 80: 383-96. [CrossRef]

Silverman, Jay G., Anita Raj, Lorelei A. Mucci, and Jeanne E. Hathaway. 2001. Dating violence against adolescent girls and associated substance use, unhealthy weight control, sexual risk behavior, pregnancy, and suicidality. JAMA 286: 572-79. [CrossRef] 
Smith, Paige Hall, Jacquelyn W. White, and Lindsay J. Holland. 2003. A longitudinal perspective on dating violence among adolescent and college-age women. American Journal of Public Health 93: 1104-9. [CrossRef] [PubMed]

Stephenson, Rob, Kieran Todd, Kristi E. Gamarel, and Sarah Peitzmeier. 2020. Development and validation of a scale to measure intimate partner violence among transgender and gender diverse populations: Protocol for a linear three-phase study (Project Empower). JMIR Research Protocols 9: e23819. [CrossRef] [PubMed]

Sterzing, Paul R., Rachel E. Gartner, Jeremy T. Goldbach, Briana L. McGeough, G. Allen Ratliff, and Kelly C. Johnson. 2019. Polyvictimization prevalence rates for sexual and gender minority adolescents: Breaking down the silos of victimization research. Psychology of Violence 9: 419-30. [CrossRef]

Testa, Rylan J., Laura M. Sciacca, Florence Wang, Michael L. Hendricks, Peter Goldblum, Judith Bradford, and Bruce Bongar. 2012. Effects of violence on transgender people. Professional Psychology: Research and Practice 43: 452-59. [CrossRef]

Walls, N. Eugene, Brittanie Atteberry-Ash, Shanna K. Kattari, Sarah M. Peitzmeier, Leonardo Kattari, and Lisa Langenderfer-Magruder. 2019. Gender identity, sexual orientation, mental health, and bullying as predictors of partner violence in a representative sample of youth. Journal of Adolescent Health 64: 86-92. [CrossRef]

Wyss, Shannon E. 2004. 'This was my hell': The violence experienced by gender non-conforming youth in US high schools. International Journal of Qualitative Studies in Education 17: 709-30. [CrossRef] 